\title{
«AYUDAS», GENERACIÓN DE INGRESOS Y SALARIOS: EXPERIENCIAS DE TRABAJO JUVENILES EN UN CONTEXTO RURAL MEXICANO
}

\author{
LUISINA GAREIS ${ }^{1}$
}

\begin{abstract}
RESUMEN
El artículo analiza cómo las juventudes que crecen y viven en un pueblo rural de la Ciudad de México satisfacen sus necesidades y cómo las heterogéneas experiencias de trabajo juveniles se relacionan con otras dimensiones de la vida (familia, territorio, género, deseos personales). A partir de la descripción etnográfica de dos historias de vida, mostramos la imbricación entre relaciones afectivas, momentos de ocio y relaciones económicas. Creatividad para generar ingresos, responsabilización por su ganancia y combinación entre diferentes formas de trabajo son características de las trayectorias juveniles analizadas.
\end{abstract}

PALABRAS CLAVES: JUVENTUDES, EXPERIENCIAS DE TRABAJO, RURALIDAD.

${ }^{1}$ Becaria doctoral CONICET. Miembro del Laboratorio de Estudios en Cultura y Sociedad (LECyS) en FTS-UNLP, Argentina. Correo electrónico: luisinagareis@gmail.com 


\title{
«AJUDAS», GERAÇÃO DE RENDA E SALÁRIOS: EXPERIÊNCIAS DE TRABALHO JUVENIL EM UM CONTEXTO RURAL MEXICANO
}

\begin{abstract}
RESUMO
$\mathrm{O}$ artigo analisa como as juventudes que crescem e moram em um povo rural da Cidade do México satisfazem suas necessidades e como as heterogêneas experiências de trabalho juvenil estão relacionadas com outras dimensões da vida (família, território, gênero, desejos pessoais). A partir da descrição etnográfica de duas histórias de vida, mostramos a imbricação entre as relações afetivas, os momentos de lazer e as relações econômicas. Criatividade para gerar renda, responsabilização por seus ganhos e combinação entre diferentes formas de trabalho são características das trajetórias juvenis analisadas.
\end{abstract}

PALAVRAS-CHAVE: JUVENTUDES, EXPERIÊNCIAS DE TRABALHO, RURALIDADE.

\section{«HELP», INCOME GENERATION AND SALARIES: YOUTH WORK EXPERIENCES IN A RURAL MEXICAN CONTEXT}

\begin{abstract}
The article analyzes how youths who grow up and live in a rural town in Mexico City satisfy their needs, and how the heterogeneous youth work experiences are related to other dimensions of life (family, territory, gender, personal desires). From an ethnographic description of two life stories, we show the imbrication among affective relationships, leisure moments and economic relations. Aspects such as youths' creativity to generate income, their own responsibility for their profit and a combination of different forms of employment are characteristics of the youth trajectories analyzed.
\end{abstract}

KEYWORDS: YOUTH, WORK EXPERIENCES, RURALITY. 


\section{INTRODUCCIÓN}

En este artículo se abordan las actividades económicas que se realizan en un pueblo rural ubicado en la periferia de la Ciudad de México, llamado San Miguel Topilejo, que posee tierras para cultivo y una amplia zona boscosa ${ }^{2}$. Allí se produce avena forrajera, maíz, frijol, horticultura, ganadería a pequeña escala. Los bosques que lo rodean fungen como una especie de barrera geográfica natural a la llegada de la urbanización (Imagen 1). Característica que coadyuva a la continua reproducción de actividades agrícola-ganaderas, prácticas culturales tradicionales y existencia de un mercado laboral interno. En los últimos años, la comunidad ha experimentado cambios sobre la base de la reducción de parcelas productivas, incorporación de actividades ligadas al sector servicio o comercio y acentuación del proceso de metropolización ${ }^{3}$. En estos procesos de transformación, las características de lo «rural»-que antiguamente se vislumbraban en oposición a un carácter «urbano»— van diluyéndose y entremezclándose, generándose un nuevo paisaje (Brenner, 2013).

En este escenario, coexisten múltiples posibilidades económicas, que van desde actividades económicas «tradicionales» — como son horticultura, animales de traspatio y prácticas extractivas (caza y recolección de manera, hongos, algas, entre otras) - a empleos asalariados formales e informales, lo cual ha favorecido la pluriactividad localmente ${ }^{4}$ (Arias, 2005; Grammont, 2008). Lo que caracteriza a muchos de los trabajos encontrados es un carácter flexible, temporal y precario propio de la iniciativa neoliberal que impuso nuevas y más agudas condiciones de explotación, sobre todo a la población juvenil. En los territorios rurales, los y las niñas de los sectores empobrecidos trabajan desde pequeños realizando diferentes actividades, lo cual consolida en las trayectorias ciertos hábitos, prácticas y formas de percibir el mundo. En este marco la pregunta rectora del artículo es cómo los y las jóvenes que viven y crecen dentro de un contexto de

${ }^{2}$ Existen ambas formas de la propiedad social de la tierra. El ejido (propiedad social) cuenta con tierras cultivables divididas en parcelas de 4 has aproximadamente cada una y posee un cerro ubicado cercanamente, llamado Ocopiasco, que es de uso común y que fue dotado por el Estado en 1936 con 1.040,59 has. Las tierras comunales poseen $10.365,28$ has.

${ }^{3}$ Principalmente debido a la llegada de nuevos habitantes, entrada de servicios y comercios y una conexión más fluida con la capital, a través de caminos y carreteras (Orihuela Jurado y otros, 2015).

${ }^{4}$ Dentro de esta discusión, algunos autores sostienen que la pluriactividad dentro de las poblaciones campesinas no es un fenómeno nuevo (Warman, 1972; Arias, 2005; Grammont, 2008). 
tradiciones rurales satisfacen sus necesidades y cómo las heterogéneas formas de ganarse la vida se relacionan con otras dimensiones de la vida de los sujetos (familia, territorio, género, grupo de pares, expectativas personales). Para ello nos centramos en las experiencias de trabajo juveniles, entendiéndolas como procesos constitutivos de los sujetos que son tanto individuales como colectivos. A partir de una descripción analítica, mostramos la particularidad que otorgan las relaciones familiares/comunitarias y las posibilidades económicas que brinda el territorio a las formas de ganarse la vida en los sectores populares rurales, naturalizando la interpenetración entre momentos de ocio, familia, amigos y generación de ingresos.

La investigación más general que enmarca este texto fue mi tesis de maestría $^{5}$, la cual describe el entramado de sistemas de normatividades (campesino, comunitario, estatal e ilegal) que se encuentran interrelacionados en el territorio. En dicha trama, las juventudes crecen y trabajan haciendo uso diferencial de distintos principios legitimadores interiorizados y reformulados (Gareis, 2018).

Luego de dicha introducción y un segmento metodológico, este escrito consta de un apartado donde se reponen los resultados de investigación sobre juventudes, ruralidades y trabajo que han servido como marco teórico y estado del arte para el análisis posterior. Se describen los postulados teóricos y metodológicos utilizados para el análisis de las trayectorias juveniles en relación con los clivajes de clase, género, edad y territorio. Luego, a través de dos historias de jóvenes ${ }^{6}$ provenientes de sectores populares, se van hilvanando los resultados que encontramos para caracterizar las formas de ganarse la vida en dicho territorio. En las reflexiones finales, se enfatiza la centralidad del trabajo en las trayectorias juveniles de sectores populares, donde las prácticas económicas rurales se constituyen como una opción a la cual siempre pueden recurrir frente al desempleo y precariedades características del sistema capitalista actual. La creatividad, responsabilización por su ganancia y la combinación entre diferentes formas de trabajo y lógicas económicas son características de las trayectorias juveniles encontradas.

${ }^{5}$ Realizada en el Centro de Investigaciones y Estudios Superiores en Antropología Social (CIESAS), Ciudad de México, con el apoyo económico del CONACYT. El director fue el Dr. Gonzalo Saraví, con quien estoy muy agradecida.

${ }^{6}$ Todos los nombres han sido modificados para resguardar la identidad de los y las sujetos. 


\section{Metodología}

La estrategia metodológica fue etnografía en su triple acepción de enfoque, método y texto, según la concepción de Guber (2001). Por un lado, constituye una concepción y práctica de conocimiento que busca comprender los fenómenos sociales desde la perspectiva de sus miembros; por otro lado, es un método abierto de investigación que se basa en el «trabajo de campo», y, por último, se brinda una descripción analítica con el fin de lograr una explicación que sea más general que la explicación nativa (partiendo de ella) y más densa que el esquema teórico inicial del investigador. Desde la etnografía se privilegia «la construcción de los datos desde una profunda y prolongada relación con los sujetos de estudio» (Grimberg, 2009, p. 85).

Desde septiembre a diciembre del 2016 residí en Topilejo de manera continua. En este período realicé y luego analicé 25 entrevistas semiestructuradas a jóvenes entre 15 y 29 años que trabajaban en el campo y en la ciudad. Los criterios de selección fueron primeramente la edad y el género. Luego, se buscó que la muestra fuera representativa en relación con la diversidad de prácticas económicas que se realizan en el pueblo. Las entrevistas se orientaron a indagar cómo eran los procesos productivos y las condiciones laborales en las cuales participaban o lo habían hecho. Además, qué relación poseía tal actividad con su familia, su historia, lugar de procedencia y expectativas futuras. El esquema diseñado para poder conocer tal información comenzaba con la estructura familiar, preguntando puntualmente a qué se habían dedicado los miembros de su familia históricamente, apoyándome con la técnica de árboles genealógicos. El segundo momento de la entrevista estaba destinado a reconstruir las trayectorias laborales. Siempre comenzaba con la pregunta «¿empezaste a trabajar desde pequeño?». A partir de allí, se iban componiendo las diferentes experiencias laborales vivenciadas en vinculación con las relaciones sociales generadas, los aprendizajes y elementos particulares de cada trabajo (salarios, contratos, cómo empezó y terminó cada experiencia, simultaneidad con la escuela, entre otros). Para concluir, el diálogo se direccionaba hacia las expectativas que tenían a futuro y en qué deseaban trabajar próximamente. La totalidad de las entrevistas fueron grabadas y fueron mayoritariamente individuales. Se llevaron a cabo en la vivienda o lugares donde trabajaban las y los jóvenes, por lo que algunas veces, al momento de la entrevista, estaban presentes otras personas que intermitentemente intervenían en la conversación. 
Dichas situaciones coyunturales fueron incorporadas como datos a la investigación ${ }^{7}$.

Además, entrevisté a veinte personas mayores de la comunidad para poder conocer, complejizar y analizar el contexto histórico y los diferentes ámbitos de socialización y oportunidades laborales disponibles para los jóvenes. Buscando ir más allá de la palabra dicha y los discursos (Quirós, 2014), la estrategia principal de producción de conocimiento fue realizar observación participante en los contextos laborales juveniles: mientras trabajaban en el campo, en una tortillería, en el mercado, en una maquila textil, en un comercio o en el bosque. Las entrevistas y registros de observación fueron procesados con apoyo del software para análisis cualitativo de datos N-Vivo 10.

La convivencia en lugares y momentos cotidianos poseyó una importancia particular en esta investigación, ya que muchas veces existe una naturalización de las «formas de ganarse la vida»-con sus relaciones, condiciones y reglas - , lo cual genera que difícilmente sean verbalizadas. Como también resulta complejo realizar las preguntas adecuadas que fomenten una reflexión o descripción de todos los elementos relacionados con la generación de ingresos. Por otra parte, esta estrategia resulta significativa, ya que considero que la mejor forma de relacionarse y entablar un diálogo fluido con las juventudes es a partir de una práctica concreta: trabajar, caminar, cocinar, realizar actividades culturales o políticas. En este sentido, busqué encontrarme con los y las jóvenes en momentos que excedieran la escena de las entrevistas con grabador en mano. Desde allí que escogí para este texto una forma de relato que logre describir analizando o analizar describiendo (Quirós, 2011) contextos concretos de diálogos y trabajos compartidos. Para lo cual reconstruí dos historias que permiten visualizar la cotidianidad territorial y vivenciarla. Con el fin de

7 Las dos historias de vida aquí reconstruidas son ejemplos de situaciones noplanificadas del trabajo del campo. La entrevista a Josefina constó de dos partes, ya que la primera sección fue realizada en el comedor de su casa y al inicio de la misma llegaron los miembros de su familia quienes, a medida que reconstruíamos la trayectoria familiar (árbol genealógico, oficio de padres y abuelos, trayectorias migratorias), se fueron incorporando a la conversación. Para la segunda parte de la entrevista (trayectoria laboral y proyectos personales), la convoqué a ella en otro espacio físico. Al segundo joven Roberto- le realicé la entrevista en la cocina de su casa. Si bien en gran parte estuvimos a solos, en otro momento ingresó la hermana a cocinar para sus hijos y participó de la entrevista, ya que también era conocida mía. 
robustecer ciertas afirmaciones, recurrí a fragmentos de otras entrevistas realizadas.

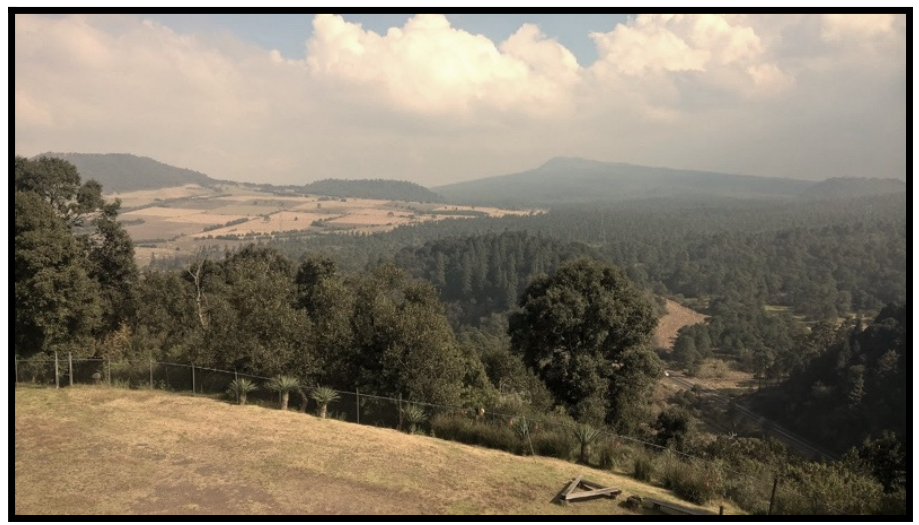

IMAGEN 1. FOTOGRAFÍA DEL EJIDO DE TOPILEJO SEMBRADO Y PARTE DEL BOSQUE QUE SON TIERRAS COMUNALES. TOMADA POR LA AUTORA.

\section{TRABAJOS Y TRAYECTORIAS JUVENILES EN RURALIDADES}

Diversos estudios han enfatizado los factores estructurales asociados a la precariedad e inestabilidad laboral que influyen en las formas de trabajo juveniles, como los procesos de reestructuración productiva, el escaso dinamismo del mercado de trabajo y las reformas estructurales asociadas al modelo neoliberal ${ }^{8}$ (Rojas García, 2002; Pacheco, De la Garza y Reygadas, 2011). Más allá del peso determinante de estos aspectos, en este texto nos abocamos al análisis de las experiencias laborales juveniles - prácticas, representaciones y sentires- y los procesos de socialización a partir de los cuales se internalizan las formas de hacer y ser en la vida cotidiana (Míguez, 2008). La premisa de la cual partimos es que las relaciones económicas surgen como respuesta a la intensión de satisfacer necesidades en contextos sociales e históricos concretos (Thompson, 1979; Narotzky, 2004). Y que, tal como las

\footnotetext{
${ }^{8}$ En México, la implementación del neoliberalismo comienza en 1986 después de la crisis de 1982 (Rojas García, 2002). Desde entonces, se disminuyó el gasto público, los sindicatos perdieron poder y se agudizó la desregulación estatal, entre otras medidas que tuvieron como efecto el incremento de la flexibilización y precarización laboral (Rojas García, 2002). La contraparte ha sido un aumento considerable del sector informal (Bayón, 2006). Con un constante abaratamiento de la mano de obra, los índices de pobreza también se han incrementado (Pacheco, De la Garza y Reygadas, 2011).
} 
encontramos hoy, son producto de la historia particular de la expansión del capitalismo (Trinchero y Balazote, 2007). Dentro de este, existe una diversidad de formas de trabajar que son integrales y centrales para el sistema más allá de las clásicas relaciones salariales (Narotzky, 2004). Dicha heterogeneidad ha sido englobada por Narotzky y Besnier (2014) bajo el concepto de «ganarse la vida», la cual, según sugieren, debe indagarse en relación con las posibilidades objetivas y subjetivas de los sujetos y a las expectativas futuras.

Las experiencias de trabajo se constituyen por las relaciones concretas que se establecen en dichas prácticas económicas y por la conciencia práctica puesta en juego (Thompson, 1981). Cada experiencia es un proceso constitutivo de los sujetos (Scott, 2001), ya que a través del trabajo se producen y reproducen las propias condiciones sociales de existencia (objetivas y subjetivas), como también se crean los sentidos, las formas de percibir el mundo y decidir - dentro de las posibilidades que tenemos - qué hacemos en él. Es un proceso social e individual (Williams, 2000 [1977]). Cada experiencia laboral puede estar conformada por diversas y simultáneas actividades, y estar atravesada por diferentes modelos ideológicos clasificatorios (Scott, 2001).

En relación con las infancias y juventudes, tales experiencias deben ser interpretadas en el marco de los procesos de socialización en los cuales están inmersos. Lahire define la socialización como el proceso por el cual se van moldeando las «disposiciones mentales y comportamentales a través de las formas que toman las relaciones de interdependencia con las personas que le rodean de modo más habitual y duradero» ${ }^{9}$ (2006, p. 24). En el presente artículo se van tejiendo diferentes ámbitos socializadores que influyen en las prácticas, estilos juveniles y expectativas futuras. Estos son: la familia, el territorio y las relaciones comunitarias, el grupo de pares y el trabajo mismo.

Los estudios en antropología de la juventud han hecho sus principales aportes en relación con quienes viven en las ciudades, observando que tales trayectorias son cambiantes, zigzagueantes, inestables, erráticas y heterogéneas respecto a los trabajos realizados y saberes asociados (Mora Salas y De Oliveira, 2014; Machado Pais, 2007; Kessler, 2004; Jacinto, 2010). Es decir, no se observan trayectorias lineales de transición hacia la adultez marcadas por el pasaje de la escuela al trabajo, constitución de una familia propia e independencia

9 Este autor propone que actualmente los jóvenes experimentan socializaciones múltiples, que se componen básicamente de: el grupo de pares (teniendo especial relación con la industria cultural), la escuela y la familia (Lahire, 2006). 
en la vivienda, en el camino de alcanzar la autonomía respecto a su familia de origen (Saraví, 2006). Si bien este modelo normativo continúa operando, las condiciones estructurales ya no garantizan su realización, especialmente en los sectores desfavorecidos (Dávila León y Ghiardo Soto, 2008). Dentro de los estudios sobre mercados laborales juveniles se hace énfasis en que los y las jóvenes se exponen a peores condiciones laborales que los adultos: más horas trabajadas, sin salario o muy poco, sin seguro social, sin contrato laboral ni lugar de trabajo (De Oliveira, 2011; Busso y Pérez, 2016). Esta situación se recrudece entre mujeres y quienes habitan áreas rurales (Román, 2003; Longo, 2009; De Oliveira, 2011; Caputo, 2004). En estos últimos, además, aparece una sobrecarga de esfuerzo y horas dedicadas a los trabajos de cuidado y/o autosubsistencia, referida muchas veces como doble jornada (Espino, 2012; Assusa y Chaves, 2019).

Las trayectorias laborales juveniles de esta investigación, en consonancia con los resultados de los autores mencionados, se caracterizaron por «saltos» permanentes entre diferentes trabajos asalariados, constando de tres etapas. La primera se basa en una búsqueda permanente sustentada por una disponibilidad de agarrar cualquier trabajo en relación con la valoración de «hacer de todo un poco» (Roberti, 2016; Assusa, 2017). La segunda, una vez en el trabajo — los cuales generalmente implican gran esfuerzo físico-, buscan obtener para sí nuevas habilidades, aprender, mientras que ingenian maneras de complementar sus ingresos en relación con el dinero ganado por su (escaso) salario. Tercera, frente al primer inconveniente encontrado - por injusticias patronales, problemas personales o deseos incompatibles con ese trabajo-, renuncian o dejan de asistir (Gareis, 2018, 2019). La duración de tales experiencias suele ser breve (Roberti, 2016).

Los estudios de las juventudes rurales trabajadoras han sido menos prolíficos en la historia académica (Román, 2003; Kessler, 2006; Roa, 2015). En los últimos años se han hecho avances significativos, primando los cambios experimentados en tales territorios y las estrategias adoptadas por las juventudes y sus familias (Gareis, 2019). Se ha señalado, por ejemplo, la mayor importancia de ingresos por tareas no agrarias (Torres-Mazuera, 2012), formas de trabajo de sectores periurbanos en la agricultura (Roa, 2013), la creciente pluriactividad rural (Grammont, 2008), el tránsito temporal de jóvenes entre las ciudades y las comunidades rurales para conseguir recursos (Carneiro, 2007). Hay quienes han focalizado el éxodo rural juvenil sobre la base de que «los jóvenes han perdido el interés en ocuparse de las actividades agropecuarias» (Salas y González, 2014, 
p. 302), en las escasas posibilidades económicas que poseen en sus territorios (Brumer, 2007), la menor accesibilidad a la educación formal (Aparicio, 2007) y/o la absoluta autoridad paterna ${ }^{10}$ (Bartolomé, 1975). Otros autores han buscado responder cómo viven y trabajan las juventudes en los contextos rurales actualmente (Padawer, 2010, 2014; Roa, 2013; Urteaga, Pacheco y Román, 2012). Por ejemplo, Carneiro y de Castro (2007) describen las múltiples estrategias $^{11}$ que emprenden las juventudes para permanecer en los contextos rurales, señalando la valorización positiva que poseen de la vida rural.

En las trayectorias aquí analizadas, muchas familias pueden categorizarse como unidades familiares campesinas. Sin entrar en la amplia discusión existente respecto al campesinado (Wolf, 1971; Bartolomé, 1975; Warman, 1972; Palerm [1980]2008; Bartra, 2006), las definiremos como «productores agropecuarios que desarrollan sus actividades productivas en tierras sobre las que tienen algún grado de control (ocupación, arriendo, aparcería, propiedad) y que basan la organización de su producción — tanto para el mercado como para la subsistencia del grupo doméstico - en la utilización del trabajo de su familia» (Aparicio, 2007). En estas unidades opera una división del trabajo por género y edad, predominando la incorporación de todos los miembros de la familia en las actividades productivas y reproductivas — tanto domésticas como agrarias-, sean destinadas al autoconsumo o la comercialización (Palerm, [1980]2008; Baranger, 2008). Estas actividades involucran un proceso formativo informal e invisible cuando se realizan bajo la contención y acompañamiento de las familias, contribuyendo una temprana socialización al mundo del trabajo (Aparicio, 2007; Padawer, 2010, 2014). Es decir, tales experiencias de trabajo presentan un carácter positivo en la formación subjetiva e identitaria de los sujetos ligadas a

${ }^{10}$ Bartolomé (1975), en un estudio clásico sobre las familias misioneras de colonos observó que los padres controlaban todos los aspectos de la vida de sus hijos, quienes debían trabajar desde temprana edad a la par de los adultos en la unidad familiar, siendo el resultado una fractura intergeneracional que impulsaba a las juventudes a migrar hacia las grandes ciudades.

${ }^{11}$ Carneiro y De Castro (2007) señalan las estrategias familiares para permanecer en el campo (diversificación de producción a través de combinación entre productos animales y vegetales y de prácticas de autoconsumo y comercialización) y otras para superar el aislamiento (extender la vida cotidiana más allá de los límites de la comunidad local, acceder a bienes y servicios disponibles en los centros urbanos; profundizar las redes familiares de apoyo para las experiencias de migración; educación de las generaciones jóvenes). 
un saber-hacer (Roa, 2015) que se entrelaza con el juego, la observación y la práctica (Urcola, 2010).

En este artículo, partimos de la juventud como una categoría sociocultural y relacional construida según los contextos particulares históricos y sociales (Bourdieu, 1990; Feixa, 1998; Margulis y Urresti, 1998; Chaves, 2010, 2013). Un concepto que ha sido muy útil y utilizado en los estudios sobre juventudes es el de trayectorias sociales (Dávila León y Ghiardo Soto, 2018), que ha permitido analizar las condiciones «iniciales» de las cuales parte el sujeto — apreciando el peso determinante de las familias para definir la «posición de origen» (Mora Salas y De Oliveira, 2014) - y cómo, a través de la interdependencia entre diferentes dimensiones (familiar, social, laboral, educativa, política, cultural), van modelando su camino (Bourdieu, (1998)[1979]; Mutuverría, 2020). Así, la trayectoria ha permitido sopesar la relación y pesos mutuos en la compleja relación entre la estructura y la agencia de los sujetos (Bourdieu, (1998)[1979]). Las juventudes, en sus procesos de construcción de autonomía, pueden utilizar los capitales incorporados (Assusa, 2017), tensionar ciertos aspectos de la cultura parental o de la hegemónica (Hall y Jefferson, 2014[1993]; Feixa, 1998) y/o tomar decisiones con las cuales logran resolver sus necesidades cotidianas, aunque puedan contribuir a reproducir sus posiciones respecto a la estructura de edades, de clase y/o de género (Willis, 1988[1977]).

En el análisis de las trayectorias juveniles que presentamos aparece un elemento constitutivo que no ha sido cabalmente problematizado por los autores anteriores: el territorio. Entendemos al territorio como una construcción social no solo definido por las características físico-geográficas y ambientales, sino por - y en interacción con- las relaciones sociales, políticas, económicas y culturales entre los actores (Sosa, 2012), generadas en cierto espacio-tiempo y vinculadas necesariamente a las relaciones de poder que controlan dicho espacio (Haesbaert, 2013). Maurice Godelier (1989) llama territorio a aquella porción de la naturaleza en la cual una sociedad encuentra las condiciones y medios de existencia que permiten la reproducción de la vida de hombres y mujeres, de la sociedad y de dichos recursos a través del acceso, control y uso de los medios materiales de existencia visibles y de las potencias invisibles que lo componen (conductas simbólicas). El autor explica que «en nuestra sociedad, esas actividades se llaman "trabajo"» (1989, p. 109). En este sentido, para comprender el devenir de las trayectorias juveniles nos enfocamos en las experiencias de trabajo posibilitadas en y por dicho territorio; este es entonces una dimensión social constituyente de las primeras. Si bien las fronteras se desdibujan cada vez 
más, existiendo actualmente un continuum rural-urbano (Brenner, 2013), las formas de ganarse la vida en los «contextos rurales» se encuentran marcadas por un vínculo particular con la naturaleza y por relaciones sociales de interconocimiento que generan formas de organización particulares (Carneiro y Guaraná de Castro, 2007).

\section{LA UNIDAD DOMÉSTICA CAMPESINA: GÉNERO Y TENSIONES JUVENILES}

Josefina, quien tiene 25 años actualmente, comenzó desde pequeña trabajando dentro de la unidad doméstica campesina, la cual funciona como una «unidad de producción y consumo», donde se guían principalmente por una lógica de valores de uso con una íntima relación con el sistema capitalista (Palerm, 2008[1980], p. 306). Esta familia posee cuatro hectáreas, donde realizan horticultura, se alimentan de su producción y la venden en el mercado. El dinero obtenido se destina, principalmente, a la reproducción familiar y el restante «se lo reparten» equitativamente entre los cuatro miembros de la unidad. En una conversación con la familia me explicaban:

Luisina: ¿Y empezaron a trabajar desde chiquitos?

Javier: En realidad, como al principio era así como «bueno, vamos aquí a jugar, a jugar con la tierrita, acá», pero pus... no fue como un trabajo así, fue como una ayuda como parte... Como una educación, pus hay que hacer algo.

Madre: Yo pienso que sí fue un trabajo porque, de hecho, ya de chico tu papá «vas a hacer esto» o sea en el campo... «van a desyerbar», o sea desde chico usted ya ha estado trabajando. Que también se ha dedicado como él dice a su estudio, pero pues bueno yo lo veo como un trabajo ya.

Josefina: En los trabajos del campo son más pesados, entonces pues aquí se necesitaba cooperar.

Padre: Pues sí... de hecho por eso, creo yo, que se fue habituando al trabajo del campo y por eso ya no se quiso ir a trabajar a otro lado (...).

Luisina: ¿Cuál es la diferencia entre ayudar y trabajar?

Padre: Aunque no recibía plata, pero pues es trabajo. O sea es como una obligación de cooperación porque por un lado va aprendiendo y, por otro lado, 
se va formando el hábito y no estaba de ocioso. (Padre, madre, Javier de 27 años y Josefina de 25 años)

Un rasgo característico de las actividades económicas que realizan los infantes es nombrarlas de diferentes maneras: «colaboración», «ayuda», «obligación de cooperación». Ciertamente la «ayuda»y el «trabajo» presentan, para los actores, diferencias relacionadas con recibir o no ingresos y a las responsabilidades y saberes puestos en juego en los procesos laborales. Sin embargo, estas diferencias son tan ambiguas y los límites tan porosos, que no solo existe un continuum entre ambas, sino que las juventudes pueden realizarlas simultáneamente o, de manera reversible, ir y venir entre estas «diferentes» formas de trabajar (Gareis, 2018). La «ayuda», entonces, desplaza - e invisibiliza - la actividad que es menos legítima en otros sectores sociales: trabajar en la infancia ${ }^{12}$. La madre, apoyada en los «usos y costumbres» de la cultura campesina, asume que tales actividades eran un trabajo.

Esta «obligación de cooperación», como lo ha conceptualizado el padre de Javier y Josefina, presenta para ellos dos objetivos: aprender un oficio y hacerse un hábito. El trabajo es uno de los ámbitos de socialización donde se trasmiten valores, normatividades e ideas que se relacionan con el estilo de vida rural y con la forma de trabajar dentro del proceso productivo familiar, comunitario, campesino. Josefina menciona que «ya no le cuesta» el trabajo en el campo porque lo aprendió desde pequeña, se le fijó en el cuerpo; se acostumbró a las posturas agachadas para sacar la hierba, aguantarse las horas bajo el sol o el frío y lluvia en invierno (Roa, 2013). Entre el juego y las tareas diarias, se incorpora la concepción del hogar como unidad de producción y consumo, en la cual todos sus miembros están involucrados, más allá del destino que posea lo producido. Narotzky (1997) sostiene que en este tipo de trabajos ocurre una imbricación entre las «relaciones afectivas», que no se encuentran directamente ni ideológicamente referidas al mercado, con «relaciones laborales» estructuradas directa y explícitamente al mercado. Esta composición es la que se va consolidando en la cotidianidad del trabajo.

Bajo la conceptualización de ayudar se nombran también los trabajos domésticos (limpiar, cocinar y cuidar) que realizan las niñas. Estas actividades

${ }^{12}$ Ariel Wilkis (2013) arriba a una conclusión similar al analizar las etiquetas que se usan para describir ciertas prácticas ilegales como «comercio» para la venta de drogas, «réplicas» para las copias ilegales de «cosas originales» y «empeño» para un tipo específico de intercambio dentro del barrio. 
forman parte de la interiorización de roles de género socialmente asignados según sexo de origen, llamada socialización de género (Espino, 2012). Es relevante visibilizar tales tareas como trabajos, ya que son un aporte fundamental en las estrategias de reproducción de las familias (Longo, 2009; Assusa y Chaves, 2019).

Saliendo de la escuela me iba a almorzar con mami y me decía «¿Qué quieres? Tacos, pescados». Y así y ya me compraba y «ahora ya vete a la casa, allá debe estar tu hermana y la ayudas a limpiar la casa» y ya venía y sacudía la sala y mi hermana, pues estaba haciendo la comida, limpiando, lavando trastes, y mi hermano estaba afuera trabajando. (Josefina, 25 años)

La demarcación inconsciente y completamente naturalizada de la niña dentro de la casa realizando los quehaceres del hogar y el niño afuera ayudando al padre, normaliza el modelo de hombre proveedor que está profundamente arraigado en este territorio (Gareis, 2018). Este saber-hacer incorporado es capitalizado para la inserción laboral fuera de la unidad familiar como cuidadoras, en limpieza o en cocina; todos realizados en condiciones precarias, con bajos salarios y sin protección social (Assusa, 2017). Cuando tienen sus propios hijos, estas experiencias les permiten articular y conciliar los trabajos remunerados y los de cuidados (Assusa y Chaves, 2019).

Josefina realizó toda su carrera escolar en la ciudad con la ayuda económica de sus padres, trabajando en la huerta con ellos y vendiendo diferentes cosas: dulces en el colegio, pulseras cuando se iba de viaje, pulques ${ }^{13}$ en el pueblo, verduras con una carretilla ${ }^{14}$. En la urbe conoció y practicó una de sus

${ }^{13}$ Pulque es una bebida fermentada tradicional que se elabora a partir del agave o maguey. En muchos pueblos rurales mexicanos, las familias que tienen plantas producen la bebida y la comercializan localmente, ya que la misma no puede ser envasada ni industrializada porque luego de dos o tres días se vuelve agria. En Topilejo crecen dichas plantas por sus condiciones físico-geográficas. Josefina se dedica desde hace años a vender pulque en el pueblo los domingos con sus amigos, con lo cual obtienen dinero para los proyectos culturales, y en caso de no venderlos, los consumen y se divierten. Otro joven me decía que vendía la flor del maguey, que crece en el bosque, cuando encontraba una.

${ }^{14}$ Josefina, antes de incorporarse nuevamente a trabajar con su familia, vendió verduras que se producían en su casa, con una carretilla por el pueblo y se quedaba con el dinero de las ventas sin «pagar» ni «trabajar» en la producción. Ahora entiende, según me relató, que eso no era justo para el resto de su familia. Cree que aceptaron tal situación porque recién se había separado y su hija era pequeña, pero también considera que le tenían «lástima». 
pasiones: el teatro y la danza. Este tipo de relatos son muy comunes entre los y las jóvenes de Topilejo, por ejemplo, Edgardo de 22 años me decía que mientras asistía al colegio «vendía dulces adentro (...) era ilegal porque está prohibido el comercio en el $\mathrm{CCH}^{15}$. Compraba dulces en la dulcería y yo traía una mochilita (...) Sí generaba porque aparte yo era activista, me juntaba con los rebeldones, con los comunistas, entonces éramos muy conocidos. Era para los gastos, para los viernes, para invitarle un café a la enamorada, cosas así» (Edgardo, 22 años). Mientras practican un deporte, asisten a la escuela o realizan alguna actividad política, ingenian maneras de generar los recursos que necesitan en ese momento. Volveremos sobre este punto en el siguiente apartado.

Josefina proyectaba ingresar a la universidad alentada por su familia porque «siempre quisieron que estudiáramos para que no trabajáramos en esto (en el campo), pero terminamos acá y me gusta, eso es lo importante», afirma ella. Sin embargo, a los 20 años se embarazó y comenzó una trayectoria laboral fuera de la unidad familiar. Con residencia particular y obligaciones para ganar su propio sustento, se vio forzada a abandonar el proyecto estudiantil. Tres años después, como consecuencia de la separación con su esposo y luego de varios «saltos» a través de diferentes experiencias de trabajo precarias e informales por la ciudad, decidió volver a trabajar dentro de la lógica de producción campesina junto a sus padres y hermano. Esta decisión le produce tensiones en torno a la autonomía antes alcanzada, con las cuales debe lidiar cotidianamente.

A mí salirme ocho días aquí me causa problemas... no puedo salir porque siempre hay cosas que hacer... por ejemplo ahorita siendo domingo y siendo día de descanso podría estar allá arriba con los cuates del Corredor ${ }^{16}$. No sé, podría hacerlo, pero en este caso no lo hago porque sé que aquí hago más cosas. Con las salidas siempre ha sido así y si me detengo a pedir permiso, ¿o sea ahorita tú solo avisas que te vas? Más bien avisé hace tres meses que iba a salir en mi cumpleaños (...) Para poder salir tuvimos que ver si no íbamos a tener muchas cosechas y si no teníamos mucho trabajo encima. (Josefina, 25 años)

Esta joven ha experimentado los «beneficios» del trabajo en relación de dependencia: salario, horarios fijos y la posibilidad latente de renunciar. Lo que

${ }^{15} \mathrm{CCH}$ hace referencia al Colegio de Ciencias y Humanidades de la UNAM. En la actualidad, hay cinco planteles dedicados a la enseñanza media, sin embargo, ninguno se ubica en San Miguel Topilejo ni en los pueblos rurales cercanos.

16 «Cuates» es un palabra del lunfardo para referirse a los amigos y amigas. El «Corredor» hace referencia a una organización política-cultural de jóvenes de Topilejo. Ver pie de página $\mathrm{N}^{\mathrm{o}} 20$. 
se traduce para ella en una percepción de mayor libertad individual ${ }^{17}$ que, frente al vínculo de parentesco, el recambio permanente entre trabajos y la renuncia no es una opción viable. En la unidad productiva familiar no existen horarios fijos ni salario regular y se trabaja a razón de la necesidad, del ciclo agrícola o la demanda del mercado. Habiendo interiorizado tal forma de trabajo desde pequeña, comprende y comparte las obligaciones que posee, pero siente coartados sus sueños y proyectos personales (viajar, realizar proyectos culturales, estar con sus amigos). Josefina misma encuentra una injusticia si no se atiene a las normas familiares, ya que «ahora repartimos las cosas entre cuatro», aunque no encuentra la manera de abrir un espacio de negociación para satisfacer todas sus necesidades como desearía (Carneiro, 2007). Explicitadas las tensiones juveniles, me explica por qué considera que esa forma de trabajo es hoy la mejor opción que posee:

Pensé «tal vez yo no pueda ganar (en el campo) lo que pudiese ganar vestida de tlacuache ${ }^{18}$, bien pintada y tacos y minifalda por allá abajo y, aparte, el maltrato de las jerarquías, (mejor) vivir en casa con mis padres, mi hija y mi hermano». Todo el tiempo rodeado de ellos, no hay necesidad de que te maquilles ni te lastimes la columna con los tacones. Me pongo unas botas y salgo a desyerbar o a cortar las flores de calabaza a las 7 de la mañana y sin problema puedo regresarme a tomar un café, puedo llevar a mi hija a la escuela, que mi hija me ayude. (Josefina, 25 años)

Josefina logra articular el trabajo por el cual consigue los recursos monetarios con los de cuidado de su propia hija, en relación con que los límites entre estas tareas son especialmente difusos dentro de la unidad campesina ${ }^{19}$. Al igual que a su madre - quien, aunque no realiza labores agrícolas, es contabilizada dentro de las ganancias colectivas-, ella puede destinar tiempo al cuidado de su hija, el cual, siente, no tendría si trabajara afuera. Además, admite que dicha «forma de ganarse la vida» le permite combinar e intercalar diferentes

\footnotetext{
${ }^{17}$ Paul Willis explica que estas «aparentes libertades» son «libertades capitalistas (que) son potencialmente libertades reales y el capitalismo hace la apuesta, que es la esencia de la reproducción, que las libertades puedan ser usadas para el auto-condena» (Willis, 1988[1977]: 206).

${ }^{18}$ Tlacoaches, o también llamada zarigüeyas, es un mamífero marsupial con una capa de pelo corto y otra de pelo largo y duro. La expresión está siendo usada para referir a una vestimenta vistosa pero desagradable e incomoda, muy alejada al estilo juvenil que utiliza Josefina en su trabajo (Gareis, 2018).

${ }^{19}$ Las lecturas desde la economía feminista han relevado que esta condición da paso a una subvaloración de las actividades realizadas por las mujeres (Espino, 2012)
} 
actividades como, por ejemplo, realizar actividades culturales y políticas dentro del pueblo ${ }^{20}$. Cuenta con más tiempo libre diariamente, ya que no debe viajar dos horas hacia la ciudad para trabajar y vive con escasos recursos, porque no paga alquiler y produce su propio alimento. Se debe a la interpenetración entre las relaciones afectivas y económicas que naturalizó desde pequeña.

Los estudios rurales muestran que los motivos por los cuales las juventudes eligen vivir en el campo son la tranquilidad, las redes familiares y comunitarias que brindan recursos materiales y contención emocional, el contacto con la naturaleza y los valores e identidades compartidas, sobre todo cuando conocen o han vivenciado las dificultades encontradas en las grandes ciudades (inseguridad, alta competitividad por acceso a puestos laborales, hacinamiento de viviendas, anonimato, entre otras) (Carneiro, 2007). Josefina suma a estos motivos los trabajos de cuidado, las actividades recreativas y los estilos juveniles asociados. Sus expectativas futuras son vivir en su tierra, hacer policultivos, tener un herbolario y poder controlar sus usos del tiempo:

«Mi idea es trabajar para hacer una casita pequeña para mi hija y el demás dinero que vaya generando solo va a ser para viajar. Cuando tenga mi propia siembra y pueda controlar los tiempos, entonces ya voy a poder decidir si irme o no irme» (Josefina, 25 años).

\section{ENTRE EL CAMPO Y LA CIUDAD: COMPLEMENTARIEDAD, CREATIVIDAD Y ESTILOS}

Roberto, de 20 años, desde muy pequeño iba junto con sus hermanos a la chacra de su familia a plantar y cosechar maíz, que luego vendían en el centro del pueblo (Imagen 2). En un contexto de pobreza y urgencias permanentes, él y sus hermanos realizaban algunas picardías para poder satisfacer sus necesidades.

Luisina: ¿Y era bueno (trabajar en el campo con la familia que vendía los elotes)?

\footnotetext{
${ }^{20}$ Josefina forma parte de un grupo de jóvenes que realizan actividades culturales y políticas dentro del pueblo llamado «El corredor cultural». Organizan eventos de grafitis colectivos, música en vivo y una feria de libro anual, montaron una huerta comunitaria y brindan talleres de producción agroecológica de alimentos con venta de pulque y comidas de producción local. Además, realizan viajes para conocer grupos de jóvenes organizados en otras regiones del país.
} 
Roberto: Sí, era bueno porque luego también hacíamos... chanchullos, finanzas.

Luisina: ¿Por qué finanzas?

Roberto: Porque cuando no iba mi papá, pues «véndeme un ciento o 200» (de maíz) y hacíamos el bussines entre mis hermanos (porque) ya era para nosotros aparte, porque mi papá casi no nos daba dinero.

Luisina: ¿No les pagaba?

Roberto: No (...) Entonces en el día nos íbamos a cortar (maíz) y le pasábamos a dejar a mi mamá (en la feria). Luego, si mi mamá se iba a bañar, ya las docenas que vendíamos eran para nosotros. Luego juntábamos entre los tres y ya nos repartíamos igual. Luego, en la noche, nos veníamos a bañar y nos salíamos a divertir. (Roberto, 20 años)

Roberto hacía chanchullos, finanzas, bussines porque él y sus hermanos se quedaban con dinero que debía ingresar al «fondo de consumo» familiar dentro de la normatividad campesina (Wolf, 1971; Bartra, 2006), y lo utilizaban para suplir sus necesidades de ese entonces: por ejemplo, salir al baile. Diferentes estudios han enfatizado en las heterogéneas maneras que los jóvenes de sectores populares inventan o acuden para poder resolver sus necesidades, aunque con ellas transgredan ciertas normativas (Kessler, 2004; Míguez, 2008). En este caso no es la ley estatal o de la propiedad privada la que se busca sortear, sino aquellas por las que se organizan las unidades campesinas. Las diferentes formas de nombrar la participación en el mundo de la economía ${ }^{21}$ remiten a cierta ilegitimidad en estas (Wilkis, 2013; Gareis, 2018). La fuente de legitimación de tales prácticas proviene, muchas veces, de la actitud de los padres, al fingir desconocer el origen del dinero (Kessler, 2004; Míguez, 2008). Las juventudes, por su parte, elogian su ingenio o inteligencia al haber podido conseguir por sus propios medios ciertos recursos: la creatividad es una de las características de ganarse la vida en los sectores populares (Bayón, 2006; Merklen, 2000). Picardías creativas que también Edgardo puso en juego a lo largo de su trayectoria cuando vendió dulces en la escuela aunque estuviera prohibido, o

${ }^{21}$ Wilkis (2013) menciona que existen etiquetas (trucho, ilegal) que son categorías de clasificación que condenan formas innobles de participación en la economía. A su vez, los sujetos utilizan otras maneras de nombrarlas, que desplaza el término que las definía como más ilegítimas. 
Josefina, al vender las verduras cosechadas dentro del entorno familiar que ella no producía (ver nota a pie de página $\mathrm{N}^{\mathrm{o}} 14$ ).

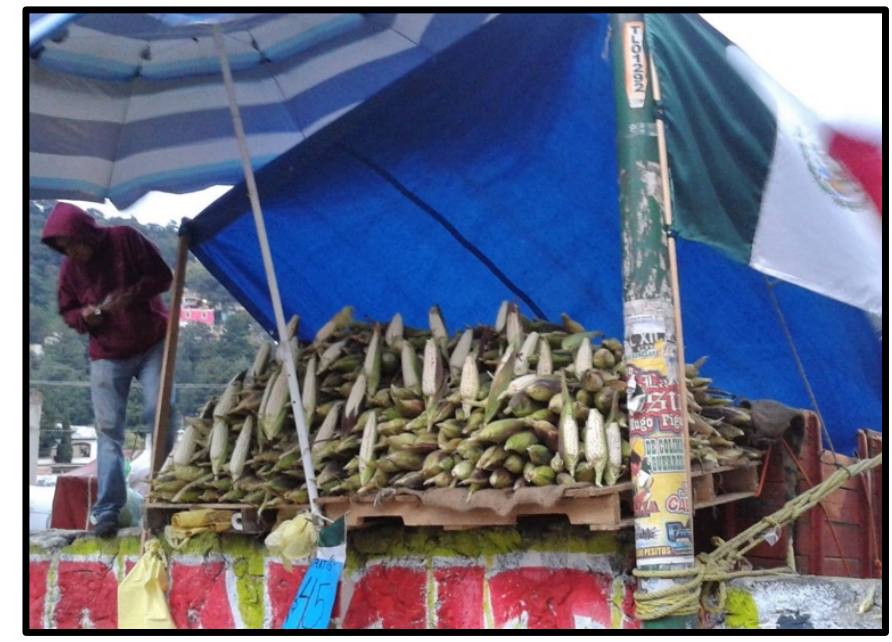

IMAGEN 2. FOTOGRAFÍA DE ROBERTO VENDIENDO MAÍZ FRESCO, COMO HACE DESDE NIÑO EN ÉPOCAS DE COSECHA. FOTOGRAFÍA TOMADA POR LA AUTORA.

A medida que los y las jóvenes transcurren en sus biografías, van teniendo nuevas necesidades, por lo que buscan obtener sus propios ingresos. Los primeros trabajos fuera del núcleo familiar son dentro del mismo pueblo en relación con la agricultura o el bosque y, para las mujeres, cuidadoras, cocineras o hacer limpieza. Ponen a disposicion las habilidades que aprendieron con sus familias para el ingreso al mercado de trabajo, es decir, logran convertir el capital educativo «informal» que adquieron desde pequeños en capital económico (Assusa, 2017).

Luisina: Y en el campo, ¿cómo funciona?

Sofía: Haz de cuenta que si haces 20 paquetes de espinacas y te las pagan a 5.50, o sea imagínate cuánto es... Aquí se maneja de tres: por día, por destajo o por manojo.

Luisina: ¿Qué es a destajo?

Roberto: A lo que puedas avanzar.

Sofía: Hasta dónde creas tú. Si te vas a las 8 y llegas hasta la esquina, pero si no ya... Luego mi abuelita dice: «Mira, me pagaron de a 
cuatro los manojos, hice tantos manojos tal día», y ganan muy poquito a la semana, 600 pesos.

Luisina: ¿Cuántos manojos se hacen generalmente, puede hacer una semana?

Roberto: Depende la persona cómo trabaje, es cansador. (Sofía (hermana) 24 años y Roberto, 21 años)

Dentro de las labores agrícolas, Roberto pasa de trabajar dentro de una lógica de producción campesina a una lógica individualista de producción; lo cual con el tiempo aprende a intercalar. Cuando la hermana de Roberto se junta con Ignacio y se embaraza a los 17 años, comienzan a convivir todos juntos (sobre la base de la imposibilidad de los sectores populares de conseguir un nuevo hogar, los hijos con sus parejas e hijos propios viven en casa de sus padres) y el cuñado le brinda diferentes oportunidades laborales por la ciudad. Se verifica que para los y las jóvenes de sectores populares, el capital social —redes personalizadas de parentesco, vecindad y/o amistad - es un recurso fundamental dentro de las estrategias laborales (Gutiérrez y Assusa, 2019), sobre todo en los primeros trabajos (Pérez Islas y Urteaga, 2001; Gareis, 2018).

A medida que transcurren en sus trayectorias laborales, las juventudes normalizan el conocido «fetichismo del salario» sobre la base de la modalidad del «trabajo a destajo», donde se paga un monto fijo por completar cierta tarea (armar paquetes de espinaca, cocer prendas en una maquila textil, vender tarjetas de crédito, entre otras $)^{22}$, sin importar el tiempo transcurrido ${ }^{23}$. Se sedimenta, así, la creencia de que «mientras más trabajan, más ganan» (Leite López, 2011), en la cual la condición juvenil permite obtener ciertas ventajas en relación con la

${ }^{22}$ Todos los ejemplos dados forman parte del acervo de las trayectorias juveniles encontradas y analizadas en Topilejo; tanto dentro de los jornales agrícolas, las maquilas de ropa y los trabajos temporales en grandes empresas de publicidad en el centro capitalino.

${ }^{23}$ Marx (1982[1872]) explica que la naturaleza del salario no varía según sea por tiempo o por pieza, pero con el último se incrementa la intensidad del trabajo, ya que es el trabajador quien está interesado en producir más y en prolongar la jornada laboral. Además, naturaliza las diferencias salariales según la capacidad individual de los obreros. 
mayor energía vital que pueden poner a disposición ${ }^{24}$ en comparación con sus pares adultos (Margulis y Urresti, 2008). La (auto)determinación de cuánto y cómo trabajar según las «necesidades» o «capacidades» individuales se vuelve dentro de los mercados flexibles una herramienta de doble filo: sirve, aparentemente, tanto al empleador como al trabajador. Esto conlleva a la (auto)responsabilzación por su ganancia, propio de los procesos de individuación (Merklen, 2013). Carla, de 26 años, justificaba que ella trabajaba para una empresa de publicidad más de doce horas en la ciudad, ya que «hacía turnos más largos porque necesitaba más dinero».

En este contexto rural, la reproducción de la vida no se limita a obtener dinero a través de la venta de la fuerza de trabajo o de mercancías, sino que pueden recurrir en cualquier momento a las posibilidades otorgadas por el entorno: «En la temporada de lluvias si te mueres de hambre aquí es de pinche menso $^{25}$, yo si no tengo chamba de albañilería o no se puede trabajar porque los días están feos, me voy al monte a juntar hongos o cazar conejos y después mi madre los vende», me decía un amigo de Roberto un día que los encontré en el monte cazando. Las caminatas en busca de hongos, madera o para cazar forman parte del repertorio de actividades donde se divierten, pasan tiempo con sus pares y generan recursos. Como se mencionó en el apartado anterior, aparece de diferentes formas una no-separación de espacios y momentos, sino que la vida social, familiar, de ocio y económica se entrelaza diariamente (Narotzky, 1997). Otras dos anécdotas ejemplifican dicha afirmación:

Es que siempre he estado generando dinero, desde niño fue como «abuelita, te ayudo en esto, pero me das esto», «tía, barro tu casa, pero me pagas tanto» (...) (Ahora) vendo suplementos para el gimnasio cuando voy a la universidad. ¿Y cómo se te ocurrió eso? Donde entreno es un gimnasio muy bueno, venden productos buenos pero muy caros, entonces yo les llevo el producto mucho más barato. Aparte soy jugador de gimber. ¿Y eso que significa? Apostador en los casinos. Como estudié ingeniería, sabemos algo de matemáticas, probabilidad

\footnotetext{
${ }^{24}$ Roa (2013), usando el concepto de Margulis y Urresti (2008), explica que en los jóvenes tareferos misioneros se observa un moratoria vital (como energía vital, en contraposición de la moratoria social propia de los sectores medios y urbanos), basada en la mayor fuerza, resistencia y posibilidad de mayor productividad que poseen por su condición juvenil, sin dejar de experimentar luego agotamiento y sufrimiento por esa forma de trabajar.

25 «Pinche menso» es una expresión compuesta por dos palabras para descalificar o insultar a una persona; «menso» es una persona falta de entendimiento o de razón.
} 
condicional. Entonces contamos cartas. Se supone que está prohibido, pero nos divertimos. (Enrique, 25 años)

Había materias que me gustaban o las hacía con facilidad y si alguien no quería hacer su tarea, yo decía: «Yo te la hago. Te cobro, pero te la hago» (...) Hubo un tiempo que estuve en un club de baile de la escuela, entonces decían: «Tenemos que comprar blusas iguales, pero ¿quién va a ir al centro?». «Yo voy». Entonces ya cotizaba precios y, si a mí me costaba 60 , yo les decía «me costó 80», y ya sacaba yo de ahí. (Carla, 26 años)

Miles de detalles, de pequeñas acciones, «picardías» inventadas que van permitiendo suplir las necesidades cotidianas. La necesidad, definida como «la urgencia de conseguir bienes para la subsistencia» (Narotzky, 2004, p. 55), entendiendo que son históricas y contextuales, es la que fomenta que los y las jóvenes cultiven relaciones económicas - por ejemplo, con los compañeros de escuela - en relaciones que generalmente no tienen este tenor. Es decir, situaciones que poseen otros objetivos, por ejemplo, el activismo de Edgardo en la escuela o la clase de baile de Carla, también se presentan como espacios para ingeniarse alguna manera de obtener mayores recursos y/o suplir alguna necesidad.

Roberto, dentro del pueblo se viste orgullosamente con estilo «charro» (botas, sombrero, ropa de jinetes) y frente a mi pregunta sobre la relación entre vestirse como charro y trabajar en el campo, me explica «no es cómo te vistas, sino más bien cómo trabajes... Porque, imagínate, si trabajas por allá abajo (en la ciudad) y te vas así vestido, se burlan». Los contrastes entre los trabajos por la ciudad y en el pueblo no implican solo lógicas económicas o jerarquías laborales, sino involucran las relaciones comunitarias, construcciones identitarias y formas de vestirse o expresarse. Después de la vergüenza que pasó por llevar sus botas de punta a un trabajo de ayudante de electricidad, Roberto comprendió que era mejor «adquirir» el estilo urbano de su cuñado: zapatillas y jeans para los trabajos por la ciudad y su «propio estilo» para los trabajos en el pueblo. En los estudios sobre estilos juveniles, se subraya que un componente fundamental de aquellos son las prácticas de consumo, al darles forma y contenido (Feixa, 1998; Saraví, 2015). Vemos aquí que las «prácticas de trabajo» también contribuyen a constituir su estilo y van forjando las subjetividades juveniles. 


\section{REFLEXIONES FINALES}

Este trabajo muestra «postulados» ya «conocidos», pero no por eso menos importantes y que, igualmente, han sido relegados en los estudios académicos actuales. Por un lado, la centralidad de las experiencias de trabajo para las juventudes de los sectores populares en su constitución como sujetos. Es decir, cómo el trabajo va modelando, influyendo e impregnándose recíprocamente de otras dimensiones sociales de las trayectorias juveniles (familia, territorio, grupo de pares, estilos juveniles). Por otro, explicitar que dichas trayectorias se producen y son producto del sistema capitalista es solo la punta del iceberg (Manzano, 2016); se trata de dilucidar cómo estas se producen, reproducen y transforman por y dentro de aquel en su heterogeneidad.

En las trayectorias analizadas, las posibilidades económicas disponibles en relación con el territorio otorgan cierta especificidad a la precariedad, informalidad y temprana inserción de los y las niñas en actividades laborales encontradas en otros sectores empobrecidos. En los contextos rurales, las tareas de autoabastecimiento (agrícolas, cría de animales de traspatio, caza y recolección) y la disponibilidad ingeniosa para generar recursos aparecen tempranamente en las trayectorias, pero se consolidan a medida que transcurren en ella. Proceso que se cristaliza en la frase «siempre he estado generando». Este hábito se traslada luego a otros ámbitos o relaciones sociales. De modo tal que encontramos una interpenetración naturalizada entre las relaciones afectivas y económicas.

Si bien muchos «adultos campesinos» no desean que sus hijos/hijas se dediquen a las actividades agrícolas, las juventudes perciben las prácticas económicas generadas en dicho territorio como una «posibilidad bajo la manga», a la cual siempre pueden recurrir frente al desempleo para «no morir de hambre». Sin embargo, proyectan realizar dichos trabajos de acuerdo a sus intereses y proyectos futuros, ya sea intercalando entre diversos trabajos, controlando sus propios tiempos o combinando amigos, familia, ocio y generación de ingresos.

RECIBIDO: 14 DE OCTUBRE DE 2020

ACEPTADO: 24 DE NOVIEMBRE DE 2020 


\section{BIBLIOGRAFÍA}

APARICIO, S. (2007). El trabajo infantil en el agro. En El Trabajo Infantil en la Argentina. MTEySS, OIT.

ARIAS, P. (2005). Nuevas ruralidades: antropólogos y geógrafos frente al campo de hoy. En H. Ávila (Ed.), Lo Urbano Rural. ¿Nuevas Expresiones Territoriales? (pp. 123-160). Cuernavaca: CRIM/UNAM.

Assusa, G. (2017). Jóvenes trabajadores: Disputas sobre sentidos, apropiaciones simbólicas y distinciones sociales en el mundo laboral. Buenos Aires: GEU.

AssusA, G. y Chaves, M. (2019). Working Lives of Youth in Poverty in Urban Argentina. En M. E. RAUSKY y M. CHAVES (Ed.), Living and Working in Poverty in Latin America (pp. 71-97). Londres: Palgrave Macmillan.

BARANGER, D. (2008). La construcción del campesinado en Misiones: de las Ligas Agrarias a los «sin tierra». En G. SCHIAVON (Ed.), Campesinos y agricultores familiares: la cuestión agraria en Misiones a fines del siglo $X X$ (pp. 33-70). Buenos Aires: Ciccus.

BARTOLOMÉ, L. J. (1975). Colonos, plantadores y agroindustrias. La explotación agrícola familiar en el sudeste de Misiones. Desarrollo económico, 15(58), 239-264.

BARTRA, A. (2006). El capital en su laberinto. De la renta de la tierra a la renta de la vida. Ciudad de México: Editorial Itaca.

BAYÓN, M. C. (2006). Precariedad social en México y Argentina: tendencias, expresiones y trayectorias nacionales. Revista de la CEPAL, (88), 133152.

Bourdieu, P. (1990) [1978]. La «juventud» no es más que una palabra. En P. Bourdieu, Sociología y cultura (pp. 163-174). Ciudad de México: Grijalbo.

. (1998[1979]). La distinción. Bases y criterios sociales del gusto. Madrid: Editorial Taurus.

BRENNER, N. (2013). Tesis sobre la urbanización planetaria. Nueva Sociedad, (243), 38-66.

BRUMER, A. (2007). A problemática dos jovens rurais na pós-modernidade. En M. Carneiro y G. de Castro, Juventude rural em perspectiva (pp. 35-52). Brasil: Mauad Editora Ltda. 
Busso, M. y PÉRez, P. (2016). Caminos al trabajo: el mundo laboral de los jóvenes durante la última etapa del gobierno kirchnerista. Buenos Aires: Miño y Dávila.

CAPUto, L. (2004). Bibliografia sobre juventud en Paraguay. Surgimiento y desarrollo desde los 80. Asunción: BASE Investigaciones Sociales.

CARnEIRO, M. J. (2007). Juventude e novas mentalidades no cenário Rural. En M. Carneiro y G. de Castro, Juventude rural em perspectiva (pp. 53-66). Brasil: Mauad Editora Ltda.

CARneiro, M. J. y DE CASTRO, E. G. (2007). Juventude rural em perspectiva. Brasil: Mauad Editora Ltda.

Chaves, M. (2010). Jóvenes, territorios y complicidades. Una antropología de la Juventud Urbana. Buenos Aires: Espacio.

. (2013). Culturas juveniles en la tapa del diario: tensiones entre el margen y el centro de la hoja. En M. Chaves y E. FidAlgo (Comps.), Políticas de infancia y juventud. Producir sujetos y construir Estado (pp. 111-137). Buenos Aires: Espacio.

DÁvila León, O. y GHIARdo Soto, F. (2008). Trayectorias sociales juveniles. Ambivalencias y discursos sobre el trabajo. Santiago de Chile: Instituto Nacional de la Juventud (INJUV).

. (2018). Trayectorias sociales como enfoque para analizar juventudes. Última Década, 26(50), 23-39.

De OliveIRA, O. (2011). El trabajo juvenil en México a principios del siglo XXI. En E. PACHECO, E. GARZA y L. REYGADAS (Coords.), Trabajos atípicos y precarización del empleo (pp. 199-228). Ciudad de México: El Colegio de México.

EsPINO, A. (2012). Perspectivas teóricas sobre género, trabajo y situación del mercado laboral latinoamericano. En V. EsQuIVEL (Ed.), La economía feminista desde América Latina: Una hoja de ruta sobre los deberes actuales en la región (pp. 190-246). Santo Domingo, República Dominicana: ONU Mujeres.

FEIXA, C. (1998). De jóvenes, bandas y tribus (Antropología de la juventud). Barcelona: Ariel.

GAREIS, L. (2018). Jóvenes, trabajo e (i)legalismos en un pueblo rural-urbano de la Ciudad de México. Tesis de Maestría en Antropología Social por el Centro de Investigaciones y Estudios Superiores en Antropología Social (CIESAS-CDMX), México.

. (2019). ¿Jóvenes rurales? Entre trabajos y estilos en un pueblo ruralurbano de México. En F. D’Aloisio, V. Schaefer y M. E. Previtali (Comps.), Estudios sobre juventudes en Argentina VI: protagonismos 
juveniles a 100 años de la Reforma Universitaria (pp. 247-262). Córdoba: Libro digital.

GODELIER, M. (1989). Lo ideal y lo material: pensamiento, economía y sociedades. Madrid: Taurus Humanidades.

Grammont, H. (2008). El concepto de nueva ruralidad. En M. E. PÉrez, A. FARAH y H. GRAMMONT (Comps.), La nueva ruralidad en América Latina: Avances teóricos y evidencias empíricas (pp. 23-44). Bogotá: Pontificia Universidad Javeriana/CLACSO.

Grimberg, M. (2009). Poder, políticas y vida cotidiana. Un estudio antropológico sobre protesta y resistencia social en el área metropolitana de Buenos Aires. Revista se Sociología e Política, 17(32), 83-94.

GuBER, R. (2001). La etnografía: método, campo y reflexividad. Buenos Aires: Norma.

GutiÉRrez, A. y AssusA, G. (2019). Estrategias de inserción laboral y capital social. Un estudio sobre jóvenes de clases populares en Córdoba, Argentina. Última Década, 27(51), 160-191.

HAESBAERT, R. (2013). Del mito de la desterritorialización a la multiterritorialidad. Cultura y representaciones sociales, 8(15), 9-42.

HALl, S. y JEFFERSON, T. (2014[1993]). Resistencia a través de rituales. Subculturas juveniles en la Gran Bretaña de la posguerra. Madrid: Traficantes de Sueños.

JACINTO, C. (2010). La construcción social de las trayectorias laborales de jóvenes. Políticas, instituciones, dispositivos y subjetividades. Buenos Aires: PREJET-IDES.

KESSLER, G. (2004). De proveedores, amigos, vecinos y barderos: acerca del trabajo, delito y sociabilidad en jóvenes del Gran Buenos Aires. Desacatos, (14), 60-84.

. (2006). La investigación social sobre juventud rural en América Latina. Estado de la cuestión de un campo en conformación. Revista Colombiana de Educación, (51), 16-39.

LAHIRE, B. (2006). Infancia y adolescencia: de los tiempos de socialización sometidos a constricciones múltiples. Revista de antropología social, 16, 21-38.

LeITE Lopes, J. S. (2011). El Vapor del Diablo. El trabajo de los obreros del azúcar. Buenos Aires: Antropofagia.

LONGO, M. E. (2009). Género y trayectorias laborales. Un análisis del entramado permanente de exclusiones en el trabajo. Trayectorias, 11(28), 118-141. 
Machado Pais, J. (2007). Chollos, chapuzas, changas: Jóvenes, trabajo precario y futuro. Barcelona: Anthropos.

Manzano, V. (2016). Tramas de bienestar, membresía y sujetos políticos: La Organización Tupac Amaru en el norte argentino. Revista Ensambles, 3(4-5), 54-71.

MARGUlis, M. y URRESTI, M. (1998). La construcción social de la condición de juventud. En H. Cubides, M. C. LAVERde y C. VAlderrama (Eds.), "Viviendo a toda». Jóvenes, territorios culturales y nuevas sensibilidades. Bogotá: Siglo del Hombre-Departamento de Investigaciones.

Margulis, M. y URresti, M. (2008). La juventud es más que una palabra. En M. MARGUlis (Comp.), La juventud es más que una palabra: ensayos sobre cultura y juventud (pp. 13-30). Buenos Aires: Biblos.

MarX, K. (1982 [1872]). El Capital. Tomo 1/Vol. 1. (11 Edición). Ciudad de México: Siglo XXI.

MERKLEN, D. (2000). Vivir en los márgenes: la lógica del cazador. Notas sobre sociabilidad y cultura en los asentamientos del Gran Buenos Aires hacia fines de los 90. En M. SvAMPA (Coord.), Desde abajo. La transformación de las identidades sociales (pp. 81-119). Buenos Aires: Biblos.

. (2013). Las dinámicas contemporáneas de la individuación. En R. CAstel, G. Kessler, D. Merklen y N. Murard (Coords.), Individuación, Precariedad, Inseguridad: ¿desinstitucionalización del presente? (pp. 45-85). Buenos Aires: Paidós.

MíGueZ, D. (2008). Delito y cultura. Los códigos de la ilegalidad en la juventud marginal. Buenos Aires: Biblos.

Mora Salas, M. y De Oliveira, O. (2014). Los caminos de la vida: acumulación, reproducción o superación de las desventajas sociales en México. Revista mexicana de ciencias políticas y sociales, 59(220), 81115.

MutuVERríA, M. (2020). Identidades juveniles y trayectorias sociales en barrios cerrados de Argentina. El caso de Nordelta. Última Década, 28(53), 152183.

NARotzKy, S. (1997). Cultura, región y trabajo en la Vega Baja del Segura. TRABAJO, (3), 89-107.

. (2004). Antropología económica. Nuevas tendencias. Barcelona: Melusina.

NARotzKy, S. y Besnier, N. (2014). Crisis, value, and hope: rethinking the economy: an introduction to supplement 9. Current Anthropology, 55(S9), 4-16. 
ORIHUELA JURAdO, I. y OTROS (2015). Estudios Metropolitanos: actualidad y retos. Ciudad de México: Instituto Mora.

Pacheco, E., De la Garza, E. y Reygadas, L. (2011). Trabajos atípicos y precarización del empleo. Ciudad de México: El Colegio de México.

PADAwER, A. (2010). Tiempo de estudiar, tiempo de trabajar: la conceptualización de la infancia y la participación de los niños en la vida productiva como experiencia formativa. Horizontes Antropológicos, 16(34), 349-375.

. (2014). Mis hijos caen cualquier día en una chacra y no van a pasar hambre, porque ellos saben: Oportunidades formativas y trabajo predial de los jóvenes en el sudoeste de Misiones-Argentina. Trabajo y sociedad: Indagaciones sobre el empleo, la cultura y las prácticas políticas en sociedades segmentadas, 22(28), 87-101.

PAlerm, Á. (2008[1980]). Antropología y marxismo. Ciudad de México: CIESAS/UAM/Universidad Iberoamericana.

PÉrez Islas, J. A. y Urteaga, M. (2001). Los nuevos guerreros del mercado. Trayectorias laborales de jóvenes buscadores de empleo. En E. PIECK GochicoA (Coord.), Los jóvenes y el trabajo. La educación frente a la exclusión social (pp. 355-400). Ciudad de México: UIA, IML, UNICEF, CINTERFOR-OIT, RET, CONALEP.

QUIRÓs, J. (2011). El porqué de los que van: peronistas y piqueteros en el Gran Buenos Aires: una antropología de la política vivida. Buenos Aires: Antropofagia.

Quirós, J. (2014). Etnografiar mundos vívidos. Desafíos de trabajo de campo, escritura y enseñanza en antropología. Publicar, 12(17), 47-65.

RoA, M. L. (2013). Tarefa que me hiciste sufrir... La emocionalidad en la constitución del self de los jóvenes de familias tareferas. Trabajo $y$ Sociedad, (20), 323-343.

. (2015). Ser-en-el-yerbal. La constitución de subjetividades tareferas en los jóvenes de los barrios periurbanos de Oberá y Montecarlo (Misiones). Tesis Doctoral en Ciencias Sociales. Buenos Aires: Facultad de Ciencias Sociales, UBA.

Roberti, E. (2016). Los sentidos (des) centrados del trabajo: Hacia una reconstrucción de los itinerarios típicos delineados por jóvenes. Última Década, 24(44), 227-255.

Rojas GARcíA, G. (2002). Estructura de oportunidades y uso de activos familiares frente a la pobreza en Ciudad de México durante años 90. En R. KAZTMAN y G. WORMALD (Coords.), Trabajo y ciudadanía. Integración y exclusión social en cuatro áreas metropolitanas de América Latina (pp. 239- 324). Uruguay: Editor Fernando Errandonea. 
Román, M. (2003). Los jóvenes rurales en Argentina. Buenos Aires: PROINDER.

SAlas, H. y GonZÁlez, I. (2014). La reproducción de la pluriactividad laboral entre los jóvenes rurales en Tlaxcala. Papeles de población, 20(79), 281307.

SARAVÍ, G. (2009). Transiciones vulnerables: juventud, desigualdad y exclusión en México. Ciudad de México: CIESAS. . (2015). Juventudes fragmentadas: socialización, clase y cultura en la construcción de la desigualdad. Ciudad de México: FLACSO/CIESAS.

Scott, J. W. (2001). Experiencia. Revista de estudios de género: La ventana, 2(13), 42-74.

SosA, M. (2012). Cómo entender el territorio. Guatemala: Universidad Rafael Landívar/Cara Parens.

ThOMPSON, E. P. (1979). La economía moral de la multitud en la Inglaterra del Siglo XVIII. En E. P. THOMPSON, Tradición, revuelta y consciencia de clase: estudios sobre la crisis de la sociedad preindustrial (pp. 62-134). Barcelona: Crítica. . (1981 [1978]). Miseria de la teoría. Barcelona: Crítica.

TORRES-MAZUERA, G. (2012). La ruralidad urbanizada en el centro de México: reflexiones sobre la reconfiguración local del espacio rural en un contexto neoliberal. Ciudad de México: UNAM, Cátedra Arturo Warman.

Trinchero, H. y BAzAlote, A. (2007). De la economía política a la antropología económica. Buenos Aires: Eudeba.

UrColA, M. A. (2010). Hay un niño en la calle: estrategias de vida y representaciones sociales de la población infantil en situación de calle. Buenos Aires: CICCUS.

Urteaga, M., Pacheco, L. y Román, R. (2012). Jóvenes rurales: viejos dilemas, nuevas realidades. Ciudad de México: Universidad Autónoma de Nayarit/Juan Pablos Editor.

WARMAN, A. (1972). Los campesinos; hijos predilectos del régimen. Ciudad de México: Nuestro Tiempo.

WiLKIS, A. (2013). Las sospechas del dinero. Moral y economía en la vida popular. Buenos Aires: Paidós.

WiLliams, R. (2000[1977]). Marxismo y Literatura. Barcelona: Península.

WiLLIS, P. (1988[1977]). Aprendiendo a trabajar. Madrid: Akal.

Wolf, E. R. (1971). Los campesinos. Barcelona: Labor. 